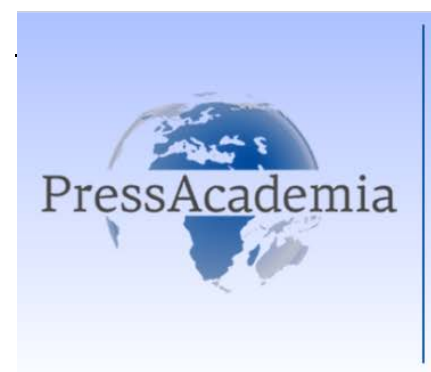

Press Academia Procedía

Global Business Research Congress (GBRC), May 26-27, 2016, Istanbul, Turkey.

\title{
EMBODIMENT OF TACIT KNOWLEDGE AS AN INSRUMENT OF COMPETITIVE STRENGTH IN THE CULTURAL MARKETS: AN EXAMPLE OF ANTAKYA
}

\section{DOI: 10.17261/Pressacademia.2016118646}

Husniye Ors ${ }^{1}$, Pelin Surmeli ${ }^{2}$

${ }^{1}$ Gazi Üniversitesi, husniye@gazi.edu.tr

${ }^{2}$ Koç Üniversitesi, psurmeli@ku.edu.tr

\begin{abstract}
With the effects of globalization that more and more has homogenized markets, consumers have begun to prefer to experiment events they perceive differently in social, cultural, geographic, technologic etc. areas. This leaning has made local and cultural factors preferential in particular in the tourism market. The cultural factors embodied in revealing the tacit knowledge behind these factors, that are the subject of the cultural market, have become the qualities of attraction sought in cultural tourism. In this context, the aim of this research is to determine the tacit knowledge factors behind the cultural market values of Antakya which is a city existing since the Paleolithic Period to the present time and, in this way, bring these factors to the global tourism market. This research conducted with the in-depth interview method has come to the conclusion that künefe (kunefah) making, silk weaving and laurel soap making is tacit knowledge original to the region while stone carving is tacit knowledge genuine to the individual.
\end{abstract}

Keywords: Cultural markets, tacit knowledge, tourism sector JEL Codes: M30, H0O

\section{KÜLTÜREL PAZARLARDA REKABET GÜCÜ ARACI OLARAK ÖRTÜLÜ BILGININ SOMUTLAŞTIRILMASI: ANTAKYA ÖRNEĞi}

\section{ÖZET}

Küreselleşmenin etkisi ile gittikçe homojenleşen pazarlarda tüketiciler sosyal, kültürel, coğrafik, teknolojik, vb alanlarda farklı olarak algıladıkları olguları deneyimlemeyi tercih etmeye başlamış, bu yönelim özellikle turizm pazarında yerel/kültürel unsurları ayrıcalıklı kılmıştır. Kültürel pazarlara konu olan unsurların arkasında saklı duran örtülü bilginin açığa çıkarılması ile somutlaşan kültürel unsurlar, kültür turizm için aranılan cazibe nitelikleri haline gelmiştir. Bu bağlamda araştırmanın amacı, Poeolitik dönemden günümüze kadar yaşayan bir kent olan Antakya'nın kültürel pazar değerleri arkasında saklı duran örtülü bilgi unsurlarını tespit etmek ve böylece bu unsurları dünya turizm pazarına kazandırmaktır. Derinliğine mülakat yöntemi ile yapılan araştırma ile künefecilik, ipekçilik ve defne sabun imalatının yöreye özgü örtülü bilgi, taş oymacılı̆̆ının ise bireye özgü örtülü bilgi içerdiği sonucu elde edilmiştir.

Anahtar Kelimeler: Kültürel pazarlar, örtülü bilgi, turizm sektörü

JEL Kodları: M30, H0O 


\section{GiRiş}

Küreselleşen dünyada belli bir yöreye özgü ürünlere ev sahipliği yapan kültürel pazarlar, ayırıcı bir rekabet avantajı taşıyan cazibe merkezleri haline gelmiştir. Bu çekim noktalarının global turizm sektöründe rekabet avantajı elde edebilmesi, ancak ayırıcılık özelliğini kullanabilmeleri ile mümkün olabilecektir. Doğal güzelliklerin yanı sıra özellikle yöresel tatlar, el sanatları, dini kültürel miras gibi değerlerin iç içe bulunduğu mekanlar, küresel turizm rekabetinde güçlü konuma gelmektedir. Bu stratejik ayrıcalık, ancak dünya turizm pazarında bu unsurların eksiksiz ve doğru biçimde belirlenmesi ön koşuluna bağlıdır. Bu bağlamda kültürel pazar değerlerinin içinde gizli duran, kelime veya sembollerin ötesinde ancak deneyim, eylem ve birikimle dışarıya yansıyan örtülü bilgi potansiyelinin ne düzeyde bilinir olduğu, sorgulanması gereken bir sorudur. Örtülü bilgi, insan eylemler ve deneyimleri ile anlam kazanan, deneyimleri ile devam eden ve kolay bir şekilde paylaşılıp aktarılamayan bilgi olarak açıklanmaktadır. Örtülü bilgi, bireye ve yöreye göre olmak üzere iki boyutta ele alınır. Yöre-odaklı örtülü bilgi; tarih, fiziki çevre, dinî ve kültürel unsurlar ile somutlaşmaktadır. Araştırmanın amacı; dünya medeniyetlerinde özellikli bir yeri olan Antakya'nın rekabette ayırıcı özellik taşıması bağlamında, kültürel pazarını karakterize eden tarihi, dini, kültürel ve fiziki değerlerinin arkasında saklı duran, sözcük veya sembollerden ziyade deneyim ve eylemlerle dış dünyaya yansıyan örtülü bilgi değerlerinin tespit edilmesi ve bu değerlerin Türk ve Dünya turizm pazarına kazandırılmasıdır. Yapılan literatür taramasında Antakya için böyle bir çalışmanın olmadığı saptanmış olup, araştırma bu yönü ile gerek turizm ve pazarlama bilim dalları açısından gerekse uygulama alanı açısından özgün bir çalışma niteliği taşımaktadır.

\section{LITERATÜR}

Küreselleşmenin tüm ekonomileri tek bir homojen pazar haline getirme gücünün yaygın kabulünün yanında bu düzlem içerisinde tüketicilerin farklı olanı bulma arayışına girdiği, farklı olabilmeye yoğunlaştığı da yaşanan bir durumdur ( Watson, vd. 2002: 923). Bu pazarlarda tüketiciler sosyal, kültürel, coğrafik, teknolojik, vb alanlarda kendilerinin farklı olarak algıladıkları olguları deneyimleyerek bu farklılığı yaşamlarına entegre etme sürecine girmişlerdir (Doğan, 2006). Küreselleşen günümüz dünyasında teknolojinin bu denli gelişmiş olması ve bu gelişmenin doğanın bir parçası olan insan yaşamının her alanına girip baskın hale gelmesi, insanı doğal hayattan koparma tehlikesinin duyumsanmasını beraberinde getirmiş ve bu süreç insanın bu baskın güçten kendini ayırma/kurtarma arayışına sevk etmiş, teknolojinin çok düşük düzeyde olduğu, bir başka ifade ile insanın doğal yaşamdan kopmamış olduğu dönemleri mevcut zamanda yaşatma içsel-arzusu ortaya çıkmıştır. İnsanın geçmişe dönüş arzusu ile yüzlerce yıllık gelenekleri sürdüren, tarihi, kültürel geçmişi olan yörelerin birer kültür pazarına dönüşmesini beraberinde getirmiştir.

\section{Örtülü Bilgi}

Bilgi; olayları ve olguları tanıma, anlama ve açıklamaya yönelik olarak eğitim, gözlem, araştırma veya deneyim yoluyla elde edilmiş ve zihinsel süreçten geçmiş olgular veya fikirler bütünü olarak açıklanmaktadır. Çevresel etkileşimlerde bilgi temel olarak açık ve örtülü bilgi şeklinde açığa çıkar. Açık bilgi, resmi ve sistematik olarak bir araya getirilmiş metin, tablo, diyagram, vs. şeklinde sunulan bilgi ( Durna ve Demirel, 2008:143) olarak tanımlanmaktadır. Örtülü bilgi ise sözlü ve yazılı olmayan, bir eylemle veya davranışla ortaya çıkan, uzun dönemli bir birikim ve deneyim ile kazanılan, kısa sürede aktarılıp paylaşılamayan (Malone, 2002:116) bilgi olarak açıklanmaktadır. Örtülü bilgi; oldukça kişisel ve özgül-bağlamlı olan ve deneyim ile biçimlenen profesyonel bir yetenek, ustalık veya kavrayıştır (Bolat, 2009). Bir başka ifade ile örtülü bilgi insanın eylemleri ile anlam kazanmakta ve kolayca aktarılamamaktadır (Johannessen, vd., 2001:7). Örtülü bilgi yalnızca sosyal etkileşimler yoluyla kazanılabilen bir başka ifade ile sosyalleşme ile diğerlerinin örtülü bilgisi haline gelebilmekte, bireyin davranışlarının, düşünce ve deneyimlerinin içinde saklı olarak zihnin içinde gizlenmiş ve bireyin davranışlarına yön vererek kişisel beceri veya pratik know-how yoluyla anlaşılabilmektedir (Turgut ve Begenirbaş, 2014:148).

Bu açıklamalar ışığında örtülü bilginin temel özellikleri şunlardır:

-ifade Edilme Güçlüğü

- Deneyimle Kazanılma 


\author{
-Usta-Çırak Iliş̧kisine Dayanma \\ -Bireye Özgü Olma \\ -Taklit Edilme Güçlüğü \\ -Yenilik ve Ayrıcalığa Temel Olma \\ -işbirliği ve Mesleki Dayanışma
}

Örtülü bilgi bireye ve yöreye göre olmak üzere iki boyuta ayrılmaktadır. Birey odaklı örtülü bilgi daha çok duygular, sezgiler, deneyim yoluyla ortaya çıktığından mesafe, yüz yüze etkileşim, paylaşım ve bilginin transferi itibariyle zorluklar yaratmaktadır. Hemen hemen her el ve işsanatının merkezinde birey bulunduğundan, bu bilginin nesilden nesile aktarılabilmesi ancak bireyler aracilığıla mümkün olabilmektedir. Bu nedenle günümüzde bir çok zanaat/sanat kaybolma riski tehlikesiyle karşı karşıyadır. Yöre-odaklı örtülü bilgi içerisinde tarih, fiziki çevre, dini unsurlar ve kültürel unsurlar yer almaktadır (Bolat, 2009). Uzun yıllar süren birikim ve deneyim ile elde edilmesi, kelime, sembol, vs dışında deneyim ile kazanılması, taklit edilme güçlüğü ve istendiği anda aktarılamaması, aktarımasının uzun zaman alması özellikleri itibariyle örtülü bilginin güçlü bir rekabet aracı olduğu söylenebilir. Örtülü bilginin somutlaştırılma yöntemleri; model alma, yüz-yüze etkileşim, fotoğraflama, hikayeleştirme, ve yazılı-görsel kaynak haline getirmedir ( Lubit, 2001; íbicioğlu ve Doğan, 2006; Bolat,2009).Bu özellikleri ile araştırmada örtülü bilginin sahip olduğu unsurların Antakya kültür pazarında olup olmadığını araştırıımışıı.

\title{
3.ARAŞTIRMA YÖNTEMI
}

Araştırmanın amacı Antakya kültürel pazarının avantajını oluşturan tarihi, dini, kültürel ve fiziki değerlerinin arkasında gizlenen, deneyim ve eylemlerle dış dünyaya yansıyan örtülü bilgi potansiyelinin somutlaştııılarak Türk ve dünya turizm sektörüne kazandırılması olduğundan, araştırma birincil veri kaynaklarına dayalı keşifsel bir araştırmadır. Araştırma amacını gerçekleştirebilecek en uygun araştırma yöntemi, birincil kaynak veri toplama yöntemlerinden derinliğine mülakattır. Bu nedenle araştırmada derinliğine mülakat yöntemi uygulanmıştır.

Araştırma planında üç aşamalı bir süreç izlenmiştir. Birinci aşamada Antakya'nın tarihi birikimi ikincil veri kaynaklarından araştırıımış ve Antakya'ya özgü olan tarih, fiziki çevre, dini ve kültürel unsurlar tespit edilmiştir. Araştırmanın ikinci aşamasında, örtülü bilginin dışarıdan değerlenebilecek olan iki özelliği dikkate alınarak, örtülü bilgi unsurlarından deneyim ve bireysel beceri özellikleri taşıyan potansiyel unsurlar araştırılmıştır. Bunun için Antakya'da doğup büyüyen, yörenin fiziki, sosyal ve kültürel çevreleri ile iç içe ve etkileşim halinde olan bir araştırmacı gazeteci-yazar ve Antakya mutfağı hakkında bir kitabı olan iki ehil Antakya'lı ile derinliğine mülakat yapılmışır. Bu mülakatlar sonucunda Antakya Ticaret Odası'nın coğrafi işaretleme yaptırdığı 'künefe', Antakya'ya özgü olarak imal edildiği ifade edilen 'ipekçilik', Antakya'lı bir sanatçının yaptığı sanat eserleri ile yöreyi dış pazarlara duyuran 'taş oymacılığı' ve Antakya'da yetişen defne ağacı meyvesinden imal edilen 'defne sabunu' örtülü bilgi potansiyelleri olarak belirlenmiştir.

Araştırmanın üçüncü aşamasında, belirlenen dört potansiyel örtülü bilgi unsurlarının, gerçekten örtülü bilgi içerip içermediğini tespit etmek amacıyla, bu unsurları imal eden ve/veya yapan imalatçı/sanatçılarla ayrı ayrı derinliğine mülakat yapılmıştır.

\section{BULGULAR}

Örtülü bilgi kaynaklarını keşfetmek için ilgili yörenin kültürel, tarihi, fiziki/doğal ve dini unsurlarını incelemek gerekir. Araştırmamızda Tunç çağına dayanan Antakya'nın potansiyel örtülü bilgi kaynaklarını ortaya çıkarmak amacıyla ilgili boyutlar ikincil veri kaynaklarından incelenmiş ve birincil veri toplama yöntemi ile araştırılmıştır.

\section{Antakya'nın Örtülü Bilgi Kaynaklarının Keşfi}

Antakya, verimli toprakları ve stratejik önemi dolayısıyla tarih öncesi dönemden günümüze, uygarlıklar boyu ilgi odağı olmuştur. Şehrin günümüz yerleşkesinin temeli Büyük İskender zamanında atılmışsa da, çevresinde yer alan Tayinat ve Açana yerleşkeleri tunç çağına dayanır ve Asur, Hitit, Babil ve Pers uygarlıklarının izlerini 
taşır (Demir, 1996: 21-22 ile bağlamış, liman kenti olması dolayısıyla da en önemli ticari merkezlerden biri haline gelmiştir.

'Hıristiyan' kelimesinin ilk kez kullanıldığı yer olan St.Pierre Kilisesi ile Antakya, Bizans İmparatorluğu döneminde en önemli dini merkezlerden biri haline gelmiştir (Demir, 1996: 21-33). Habib-i Neccar, Hz.İsa'nın oniki havarisinden biri olan St.Pierre'in Hıristiyanlığı yaymak için geldiği kentte ona yardımcı olması dolayısıyla Hıristiyan toplumu, adının Kur-an'ı Kerim'de geçmesi dolayısıyla da İslam toplumu için önem taşımaktadır. Bunların yanı sıra tarihi manastır ve kiliseleri, dünyanın en büyük üç mozaik müzesinden birine sahip olması, M.S. I. - VI. Yüzyıllara dayanan tarihi Antakya Evleri ile Antakya, somut kültürel mirası oldukça zengin bir kenttir.

Antakya'nın kültürel örtülü bilgi unsurlarını ortaya çıkararak kültürel pazarlara kazandırmak amacını taşıyan çalışmanın birincil kaynaktan veri toplamak için derinliğine mülakat yapılmıştır. Birincil araştırmaya başlarken kimlerle derinliğine mülakat yapılacağına ilişkin kararda, örtülü bilginin oluşmasında kilit faktör olan 'deneyim' dikkate alınmıştır. Bu faktör, araştırmaya katılacak olan katılımcıların seçiminde belirleyici rol oynamış ve deneyimde en uzun süreye sahip olan katılımcılarla görüşme yapılmıştır.

İkinci aşamadaki görüşmelerde öğrenildiği üzere, Antakya'da yedi adet künefeci olduğu saptanmıştır. Bunlar içerisinde kırk yılın üstünde faaliyette olan üç adet künefeci olduğu belirlenmiş ve bu künefe yapım/satım noktalarına gidilerek künefe ustaları ile derinliğine mülakat yapılmıştır.

Tarihçesi yazılı kaynaklarda 10. Yüzyıla dayanan künefe, günümüzde Arap topraklarında süregelen yöntemlerden ayrışarak Hatay'da kendine has bir gelenek yaratmıştır (Roufs ve Roufs, 2014: 208). Yapılış tekniği, diğer kültürlerde var olanın aksine peynirin kadayıf içerisinde rulo yapılması değil, iki katman arasına konulması olan Hatay künefesi, yapımında kullanılan peynirin künefeye özel olarak üretilen bir peynir olması dolayısıyla da oldukça kendine özgüdür.

Derinliğine mülakat görüşmesinde, araştırmanın odak konusu olan ilgili kültürel unsurun örtülü bilgiyi içerip içermediğini tespit etmek amacıyla literatür çalışmalarından (Bolat,2009., Doğan, 2006) yararlanılmıştır. Bu amaçla görüşme esnasında künefe ustalarına aşağıdaki sorular sorulmuştur:

\section{Usta-Çırak ilişkisi:}

-Bu işi büyüklerinizden mi öğrendiniz?

-Sizce bu yaptığınız iş nesilden nesile bir kültürel miras mıdır?

\section{Deneyim:}

-Bu mesleği uygulamadan öğrenmek mümkün müdür?

-Işinizde deneyim önemli midir?

\section{ifade Edilme Güçlüğü:}

-Yaptığınız bu işi sadece kitap, video ve benzeri kaynaklardan okuyarak, dinleyerek öğrenmek mümkün müdür? -Iş̧inizdeki deneyimin özünde bilgi var mıdır?

-Iş̧inizde deneyim zamanla mı oluşmaktadır?

-Yaptığınız işi kelimelerle anlatmak zor mudur? Görmek/izlemek mi gerekmektedir?

\section{Taklit Edilme Güçlüğü:}

-Bu işi öğrenmek için uygulamak mı gerekmektedir?

-Bu işi kelimelerden çok işi yaparak mı öğretirsiniz?

-Yaptığınız işi taklit etmek zor mudur?

-Yaptığınız iş birikime dayalı olduğu için taklidi zor mudur? 


\section{Bireysel Beceri:}

-Yaptığınız iş bireysel beceriye dayanmakta mıdır?

-'Insan', işinizde kilit unsur mudur?

\section{Kültürel Unsurlar:}

-Bu işi bir 'kültür' olarak değerlendirir misiniz?

-Yaptığınız iş Antakya'nın kültürü ile bir bütünlük taşımakta mıdır?

-Bu iş Antakya'nın kültür mirasına bir katkı mıdır?

\section{Fiziki Çevre:}

-Antakya yöresinin kendine özgü doğal güzelliği sizin için bir avantaj mıdır?

\section{Geleneksellik:}

-Yaptığınız iş geleneksel bir meslek/iş midir?

-Bu yörenizde geleneksel yöntemlerle mi yapılmaktadır?

-i̇şiniz Antakya'nın gelenekleriyle bir bütünlük oluşturmakta mıdır?

Antakya'nın potansiyel örtülü bilgi unsurlarından olan künefenin örtülü bilgiye haiz olup olmadığını tespit etmek amacıyla yapılan derinliğine mülakatta, istenilen lezzette künefe yapabilmek için usta-çırak ilişkisine dayalı olması gerektiği, künefede istenilen lezzeti yakalamak için künefe yapım aşamasındaki püf noktaları bilmek gerektiği, künefe yapımının beceri gerektirdiği, iyi bir gözlem yaparak ve zaman içinde tecrübe ederek öğrenilebildiği, künefe yapımını öğretmenin yolunun kelimelerle anlatmaktan ziyade yapımının tüm aşamasında uygulama esnasında gösterilerek olabildiği, deneyime bağı öğrenilebildiğinden beceriye ihtiyaç duyulduğu, künefenin Antakya'nın tarihinden gelen bir geleneksel ürünü ve mutfak kültürünün öncelikli öğesi olduğu, Antakya'nın fiziki çevresi ile ilişkili olduğu, bunun nedeninin künefede kullanılan girdi malzemelerinden olan tereyağı ve künefe peynirinin, bu yörede yetişen hayvanların sütünden elde edilerek yapıldığı ve Antakya geleneklerinde yemekli misafirlere olmazsa olmaz bir ikram özelliği taşıdığı tespit edilmiştir. Künefe yapımının taklidi konusunda ise taklit edilebileceği fakat istenilen lezzette bir künefe için bunun mümkün olamayacağı zira deneyimin ön koşul olduğu ifade edilmiştir. Bu verilere bağlı olarak Antakya'nın kültürel unsurlarından biri olan künefenin örtülü bilgi içerdiği sonucu elde edilmiştir.

Antakya'nın potansiyel örtülü bilgi unsurlarından bir diğeri 'ipekçilik'tir. Tarihçesi Erken Bizans Dönemine dayanan Antakya ipekçiliği, 20. Yüzyılın başlarına kadar aktif olarak devam etmiştir. Günümüzde Antakya'da ipekçilik yapan bir imalatçı olduğu saptanmış ve o usta ile derinliğine mülakat yapılmıştır. Tek kalan ipek ustasının ifadesine göre, kendileri beşinci kuşaktan bu işi devam ettirmektedirler. 1930'larda sayısı ellinin üstünde ipek dokumacısı mevcutken, günümüzde yalnızca kendisinin kaldığını, bu işi çok uzun yıllar öncesinden atalarından öğrendiklerini belirtmiştir.

İpek kumaş dokuma işlemde birkaç püf noktası mevcuttur. Su belli bir sıcaklığa geldiğinde kozaların içine atılmasını takiben görsel olarak aktarılabilen bu süreçte kozaların 'uç-bırakması'nın sağlanması gerekmektedir. Bundan sonra elde edilen ipler dokunmaları için tarihi tezgaha yerleştirilmekte, büyük bir şevkle dokunmakta, dokunan ipek kumaşlar elle yıkanmakta, kuruduktan sonra desen işlemine başlanmaktadır. Bu geleneksel yöntemi otomasyon ürünlerinden ayıran en önemli fark; ipek kumaşların daha kalın, daha kaliteli ve dayanıklı olmasıdır.

Derinliğine mülakat görüşmesi esnasında, ipekçiliğin örtülü bilgi içerip içermediğini ortaya koymak amacıyla yukarıda belirtilen sorular yöneltilmiştir. Bu sorulara alınan cevap ve açıklamalara bağlı olarak; Antakya'da yapılan ipekçiliğin usta-çırak ilişkisine dayalı, ancak ve ancak tecrübe ile öğrenilebilen, ifade edilerek aktarılmaktan ziyade uygulama ile öğretilebilen, aynı yöntemle imalatının taklit edilmesi kolay olmayan, bireysel beceriye gerek duyan, kültürel unsurları içerdiği, fiziki çevre ile ilişkili ve geleneksellik özelliğine haiz olduğu bulguları elde edilmiş olup, ipekçiliğin örtülü bilgi içerdiği sonucu elde edilmiştir. 
Antakya'nın potansiyel örtülü bilgi unsurlarından bir diğeri taş oymacılığıdır. Yapılan görüşmelerde taş oymacılığı yapan yalnızca bir usta/sanatçının olduğu bilgisine ulaşılmış ve bu sanatçı ile derinliğine mülakat yapılmıştır. Sanatçı taş oymacılığı işini babasından öğrendiğini ifade etmiştir. Sanatçı, babasının yanında onu izleyerek ve belli bir zaman sonra deneyerek taş oymacılığına başladığını, ancak sadece babasından almakla kalmayıp bu işe yaratıcılığı katarak çok farklı noktaya getirdiğini belirtmiştir. Görüşme sürecinde taş oymacılığının örtülü bilgi içerip içermediğini tespit etmeye yönelik olan sorular yöneltilmiş ve alınan açıklamalardan taş oymacılığının usta-çırak ilişkisine dayandığı, işin deneyim ile elde edilebildiği, ifade ederek aktarılmasından öte uygulama ile aktarılabildiği, tamamen bireysel beceriye bağlı olduğundan taklit edilmesinin mümkün olmadığı, fiziki çevre ile ilişkili olduğu ve yörenin kültürel birikimine bağlı olduğu, ancak kültürel unsurlarla ilişkisinin zayıf olduğu ve geleneksellik özelliğinin bulunmadığı bulguları elde edilmiştir.

Antakya'nın potansiyel örtülü bilgi unsurlarından sonuncusu defne sabunudur. Gar sabunu olarak da bilinen defne sabunu, erken ortaçağ döneminden beri yoğunlukla Suriye bölgesinde aktif olarak üretilmekte ve kullanılmaktadır. İçeriğinde zeytinyağı ve defne meyvesinden elde edilen defne yağı olmasından dolayı, zeytin ve defne ağaçlarının yetişmesine uygun iklim koşullarına sahip olan Doğu Akdeniz kıyılarında yaygın bir kullanıma sahiptir.

Antakya'da defne sabunu imal eden 14 imalatçının olduğu, bunların içerisinde beş imalatçının bu işi kırk yılın üstünde yaptıkları bilgisine istinaden, bu beş imalatçı ile derinliğine mülakat yapılmıştır. Defne sabunu imalatı için gereken hammadde defne ve zeytin ağaçlarının meyveleridir. Defne sabunu imal etmek için bu meyvelerin yağları kullanılmaktadır. Gerek defne, gerekse zeytin ağacı Antakya yöresinde oldukça verimli bir şekilde yetişmektedir. Bu geleneksel yöntem defne sabun imalatının defne ve zeytin ağaçlarının yetişebildiği fiziksel çevreye bağlı olması dolayısıyla bu unsurun fiziksel çevre ile ilişkili olduğu söylenebilir. Görüşme sürecinde defne sabun imalatının örtülü bilgi içerip içermediğini tespit etmek amacıyla sorulan sorulara verilen cevaplara istinaden; defne sabunu imalatının orta düzeyde usta-çırak ilişkisine bağlı olduğu ancak deneyim gerektirdiği, uygulama ile diğer kişilere aktarılabildiği, zaman içinde taklit edilme potansiyeli içerdiği ancak imalat sürecinde 'insan' unsuruna ihtiyaç duyduğu, bunun yanı sıra bireysel beceriye çok fazla dayalı olmadığı, yapılan işin Antakya yöresinin kültürü ile bir bütünlük taşıdığı, fiziksel çevreyle ilişkili olduğu ve geleneksellik özellik taşıdığı bulguları ile defne sabun imalatının yöreye özgü örtülü bilgi içerdiği sonucu elde edilmiştir.

\section{SONUÇ ve ÖNERILER}

Sözlü ve yazılı olmayan, bir eylemle veya davranışla ortaya çıkan, uzun dönemli birikim ve deneyim ile kazanılan, kısa sürede aktarılıp paylaşılamayan bilgi olarak tanımlanan örtülü bilgi, günümüz kültürel pazarlarında ayırıcı ve tercih nedeni özellikleri taşıyan bir değer haline gelmiş ve gelmeye devam etmektedir. Bu amaçla mevcut çalışmada, Poeolitik dönemden günümüze değin hala canlılığını koruyan Antakya'nın örtülü bilgi unsurları ortaya çıkarılmış ve bu unsurlar dünya kültür turizmine sunulmuştur. Araştırma ile ikincil veri kaynaklarından Antakya'da tarihi ve fiziki çevre (doğası), dini ( kiliseler, camiiler, manastır) ve kültürel ( Antakya evleri, İpek yolu) şeklinde yöre odaklı örtülü bilgi tespit edilmiştir. Araştırmada derinliğine mülakat yöntemi uygulanarak elde edilen bulgular aşağıda özetlenmiştir:

Antakya'ya özgü mutfak kültürünün bir öğesi olan künefenin yapımının örtülü bilgi içerip içermediğini tespit etmek amacıyla kırk yıl ve üstü bu işi yapan üç künefeci ile derinliğine mülakat yapılmıştır. Birincil kaynaktan elde edilen bulgulara istinaden; Antakya'ya özgü olan künefeciliğin örtülü bilgi içerdiği sonucuna ulaşılmıştır.

Antakya'da faaliyette olunan bir diğer unsur olan ipekçilik ile ilgili olarak yapılan araştırmada, zaman sürecinde ellinin üstünde dokumacının olduğu, ancak günümüzde Antakya'ya özgü olarak geleneksel yöntemlerle elyapımı ipek kumaşı dokuyan yalnızca bir ustanın kaldığı tespit edilmiştir. Bu usta ile yapılan derinliğine mülakatta, Antakya'daki el-yapımı ipekçiliğin örtülü bilgi içerdiği sonucu elde edilmiştir.

Antakya'da faaliyette olunan bir diğer zanaat el yapımı defne sabunu imalatıdır. Yapılan araştırmada bu mesleği kırk yılın üstünde yapan beş imalatçının olduğu anlaşılmış ve bu beş imalatçı ile derinliğine mülakat yapılmıştır. Bu mülakatta bu geleneksel yöntem defne sabunu imalatının orta düzeyde usta-çırak ilişkisine ihtiyaç gördüğü, bunun yanı sıra ifade edilme ile değil uygulama ile öğretilebilindiği, zaman içinde taklit edilebilse de deneyimli olanların ürettiklerinden daha düşük kalitede ürün elde edilebileceği, imalat sürecinde insanın emeğine ihtiyaç 
duyulsa da orta düzeyde beceriye intiyaç duyulduğu, ancak Antakya yöre insanının yaşam tarzının bir parçası olduğu, fiziksel çevredeki bitki örtüsüne bağlı olduğu ve geleneksellik özelliğine haiz olduğu bulguları ile Antakya defne sabununun büyük oranda yöre odaklı örtülü bilgi içerdiği sonucu elde edilmiştir.

Antakya'da faaliyette olunan bir diğer örtülü bilgi unsuru, taş oymacılı̆ıdır. Yapılan görüşmelerde bu işi yapan yalnızca bir usta/sanatçının olduğu saptanmıştır. Bu sanatçı ile yapılan görüşsme sonunda, yaptı̆̆ı iş her ne kadar heykeltraşıı olarak kabul edilirse de 'taş oymacılığı' olarak ifade edilmesinin daha doğru olacağını belirtmiştir. Zira sadece heykel yapmadığını, Antakya Mozaik Müzesi'ndeki eserlerden hareketle, o eserleri örnek alarak modern çağda 'Antik çağ mozaik eserleri benzerlerini de yaptığını belirtmiştir. Yaptığı işin tamamen beceri, deneyim ve yaratııılığa bağlı olduğunu belirtmiştir. Araştırma bulgularına istinaden taş oymacılığının usta-çırak ilişkisine dayandığı, deneyim ile öğrenilebildiği, uygulama ile aktarılabildiği, ancak kültürel unsurlarla ilişkili olmadığı, geleneksellik özelliği taşımadığı ve fiziki çevre ile zayıf ilişki olduğu, yörenin kültürel unsurlarıyla ilişkisinin yaratılan eserler ile ilgisi nispetinde olması dolayısıyla, bu sanatın yöreye özgü örtülü bilgi değil, bireye özgü örtülü bilgi içerdiğini ortaya koymuştur.

Antakya'ya özgü künefecilik, ipekçilik, ve defne sabun imalatının yöreye özgü örtülü bilgi içerdiği ve taş oymacılığı bireye özgü örtülü bilgi içerdiği bulgusunun kültür turizm pazarına kazandırılması gerekmektedir. Antakya halihazırda turizm seyahat acentelerinin kültür turu programlarına çok yeni girmiş bulunmakta olup, ören yerleri, mozaik müzesi, St. Pierre Kilisesi'nden oluşan bir içerik ile iç ve dış turizm programlarına alınmıştır. Antakya için daha uzun seyahat dönemi tahsis edilerek, kültür gezilerinin içerisine defne sabunu ve ipek imalatı yapan imalathanelerin eklenmesi, turistlerin bu kültürel unsurun nasıl üretildiğini yerinde görmeleri sağlanarak ziyaretin zenginleştirilmesi, ayrıca defne sabunu ile ilgili imalatçıların ortak sorunu ivedilikle çözüme ulaşmalı, geleneksel ve/veya kültür unsuru olan ürünlerimizi, otomasyon ürünlerinden ayıracak ve yasal korumaya alacak bir çözüm sürecinin ivedilikle başlatılması önerilir.

Bilgi Notu: Araştırmaya katkı veren her bir katılımcıya müteşekkiriz.

\section{KAYNAKÇA}

Bolat, S. 2009, "Örtülü Bilgi Kaynaklarının Keşfi ve Somutlaştırılması: Şirince Örneği”, Erciyes Üniversitesi iktisadi ve Idari Bilimler Fakültesi Dergisi, 24(Temmuz-Aralık): s. 339-359.

Demir, A. 1996, "Through TheAges Antakya”, İstanbul, Akbank CultureAnd Art Publications, Number:62.

Doğan, H. 2006, "Kültürel Pazarlarda Örtülü Bilginin Algılanması ve Beypazarı Örneği”, Süleyman Demirel Üniversitesi Iktisadi ve idari Bilimler Fakültesi, 11(2), s. 85-102.

Durna, U., Demirel, Y. 2008, “Bilgi Yönetiminde Bilgiyi Anlamak”, Erciyes Üniversitesi İktisadi ve Idari Bilimler Fakültesi Dergisi, 30 ( OcakHaziran), s. 129-156.

İbicioğlu, H., Doğan, H. 2006, İşletmelerde Örtülü Bilgi ve Önemi, Bursa, Ekin Yayınevi.

Johannessen, J.,Olaisen, J., Olsen, B. 2001, "Mismanagement of Tacit Knowledge: Thelmportance of Tacit Knowledge, TheDanger of Information TechnologyandWhatTo Do Aboutlt", International Journal of Information Management, 21(1), pp. 3-20.

Lubit, R. 2001, "Tacit Knowledge and Knowledge Management: TheKeysToSustainableCompetitiveAdvantages", Organizaional Dynamics, 29(3), pp.164-178.

Malone, D. 2002, “Knowledge Management A Model ForOrganizational Learning", International Journal of Accounting Information Systems, 3(2), pp. 111-123.

Turgut, E.,Begenirbaş, M. 2014, “iliş̧kisel Sosyal Sermayenin Yenilikçi Davranışa Etkisinde Örtülü Bilgi Paylaşımı Davranışının Aracılık Rolü”, Niğde Üniversitesi Iktisadi ve Idari Bilimler Fakültesi Dergisi, 7(1), s.146-160.

Watson, J.,Lysonkski, S., Gillan, T., Raymore, L. 2002, "CulturalValuesandlmportantPossessions: A Cultural Analysis", Journal of Business Research, 55, pp. 923-31. 